\title{
Educational differences in the diet of Finnish adults and the associations between education and the determinants and facilitators of dietary fat quality
}

\author{
Marja-Leena Ovaskainen ${ }^{1, *}$, Merja Paturi ${ }^{1}$, Heli Tapanainen ${ }^{1}$ and Kennet Harald ${ }^{2}$ \\ ${ }^{1}$ Nutrition Unit, National Institute for Health and Welfare, PO Box 30, FI-00271, Helsinki, Finland: ${ }^{2}$ Chronic \\ Disease Epidemiology and Prevention Unit, National Institute for Health and Welfare, Helsinki, Finland
}

Submitted 20 July 2009: Accepted 15 March 2010

\begin{abstract}
Objective: The aim of the study is to elucidate differences in adults' diet by education, and to analyse the associations between dietary facilitators, education and dietary fat quality.

Design: In all, one-third of subjects from the national FINRISK health survey were invited to participate in the FINDIET 2007 Survey. A $48 \mathrm{~h}$ dietary interview was used for dietary data and personal background data were collected by the health survey questionnaire.

Setting: Representative sample from five regions in Finland in spring 2007.

Subjects: A total of 1576 adults, participation rate $60 \%$.

Results: Oil used in cooking differed by education. Instead perception of cardiovascular risk, or the following of a cholesterol-lowering diet, were equal across all educational categories. The diet of men with low education contained less protein and carbohydrates, more fat and more SFA and MUFA than that of highly educated men. The diet of women with low education contained less PUFA, vitamin $\mathrm{C}$ and vitamin $\mathrm{E}$ than in the highly educated category. High education remained a significant determinant for the lower intake of SFA in men, and for the higher intake of PUFA in women, after adjusting for the determinants and facilitators of dietary behaviour and age. The lower intake of SFA was also associated with following a cholesterol-lowering diet in both genders. In addition to education, the intake of unsaturated fatty acids was determined by the oil used in cooking by women, and by frequent lunches served by caterers for men.

Conclusions: In dietary behaviour, awareness and reporting of cholesterollowering diet seem to indicate a tendency to control the intake of saturated fat. Health messages are likely to enhance tools for increasing the intake of PUFA, in addition to reducing the intake of SFA.
\end{abstract}

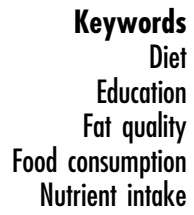

Health status and health behaviour of the Finnish population differ by educational category ${ }^{(1,2)}$. Health behaviour, including food habits, is the basis for decreasing the risk of chronic diseases ${ }^{(1,3)}$. The dietary intake of SFA has been the main dietary factor associated with cardiovascular (CV) mortality in Finland ${ }^{(4)}$. From dietary changes, the increasing consumption of vegetable oil and oil-based spreads is assumed to explain the decreasing levels of serum cholesterol ${ }^{(5)}$ and the decline in cardiovascular mortality $^{(4)}$. Serum total cholesterol has decreased in Finnish adults of all educational categories in the last decades ${ }^{(6)}$. However, more than half of the adult population in Finland still has a high serum cholesterol, $>5 \mathrm{mmol} / \mathrm{l}^{(5,7)}$. Therefore, the main message in treating hypercholesterolemia as well as for general population is to decrease the intake of SFA and increase the intake of PUFA ${ }^{(8-10)}$.

According to the Finnish Health Behaviour Surveys $^{(1,11)}$, the daily consumption of vegetables, selection of fat-free milk and oil-based spreads on bread are more common for highly educated persons. The consumption of fresh vegetables, fruit, fruit juice, whole-grain bread and cheese is more frequent among higher socioeconomic groups in all European countries ${ }^{(12-17)}$. In several ways, food choices better comply with dietary guidelines in higher-level socio-economic groups than in lower-level groups ${ }^{(11,12,18,19)}$. However, following dietary advice to change levels of dietary fat or fat quality has been reported as difficult even for motivated persons ${ }^{(20)}$ as well as for patients with $\mathrm{CHD}^{(10)}$. 
In Finland, there is still the need to change the quality of dietary fat by decreasing the intake of SFA and increasing the intake of PUFA according to the present FINDIET survey $^{(21)}$. For actions in clinical practice in the prevention of CVD, it is important to find tools that help to control the intake of saturated fat and promote healthy food choices ${ }^{(10,22-24)}$. Such tools and facilitators include availability of healthy food, healthy food at canteens, experiences and knowledge with food or increasing skills in cooking $^{(10,20,25,26)}$. In the present study, we analyse the differences in diet by level of education and further test the association between educational category, determinants and facilitators of dietary behaviour, and dietary fat quality.

\section{Materials and methods}

The cross-sectional population survey FINRISK 2007 was carried out in order to assess the risk factors of $\mathrm{CVD}^{(27)}$. A random sample of adults aged 25-74 years, stratified by sex, region and 10-year age groups, was drawn from the population register for six regions in Finland. Subjects were invited to a health examination including body weight measurement and blood sample at the local health-care centre. The invitation included a questionnaire to be completed, covering such background information as social status, health status, habitual food choices and perceptions of $\mathrm{CV}$ risk. From five regions of the FINRISK study, subjects in a subsample (33\%) were asked to participate in a $48 \mathrm{~h}$ dietary interview ${ }^{(28)}$. Of the 25-64-year-old invited subjects, $60 \%$ participated in the dietary interview of FINDIET 2007.

Education years were categorized in tertiles (low, middle and high) according to gender and birth year. The regions were aggregated as Southern Finland (the capital region of Helsinki and Turku with its surroundings) and Northern Finland (North-Karelia, Northern Savo and Oulu region). Self-rated health status, self-rated functional capacity and serum cholesterol measurement were selected as health parameters. Serum cholesterol was measured by standard enzymatic protocol ${ }^{(7)}$ from fresh blood samples. The questions for health status and functional capacity offered five alternatives, ranging from 'very good' to 'very bad'. Those giving either the answer 'rather bad' or 'very bad' were considered to have bad health or bad functional capacity. From perceptions of disease risks, the self-rated risk assessment for CVD was used. Self-rated risk assessment for CVD was based on five alternatives, ranging from 'very high' to 'very low', or 'I have a CVD'. Those answering with either of the two highest options or having a CVD were coded as having a high CV risk.

Questions concerning the determinants and facilitators of dietary behaviour were available from the background questionnaire and covered 'following a cholesterollowering diet', 'received dietary guidance after previous cholesterol measurement', 'frequent use of ready-to-eat meals', 'having daily lunch at a cafeteria or restaurant' and 'vegetable oil used in food preparation at home'. Dietary guidance after a previous serum cholesterol measurement was ascertained by a 'yes' or 'no' answer. If no previous measurement for serum cholesterol was reported, dietary guidance was coded 'no'. The question for following a cholesterol-lowering diet was answered 'no' or 'yes'. Those having more than two weekly ready-to-eat meals from supermarkets were coded as frequent users of these types of meal. The question of regular site lunch habits on working days gave six alternatives: 'no regular lunch', 'packed lunch', 'home', 'at a restaurant or bar', 'at a worksite cafeteria' or 'elsewhere'. Those having regular lunches at a worksite cafeteria, restaurant or bar were coded as frequently having catered lunches. The type of typical cooking fat used at home was identified with the options 'oil', 'high-fat spread', 'cooking margarine', 'butter-oil mixture', 'butter', 'sterol margarine', 'no fat', 'no cooking at home', from which those preferring oil were coded separately from the others.

\section{Dietary data collection}

Details of the dietary interview in FINDIET 2007 have been already published ${ }^{(21,28,29)}$. The interview covered the diet of participants over the $48 \mathrm{~h}$ before interview. It began by asking about meals eaten yesterday and continued by enquiring into meals taken on the day before yesterday. Identification of each eating event was principally based on the name of the eating occasion which was given to it by the subject. The interviewer selected the meal name from the following alternatives: breakfast, lunch, dinner, drink, evening snack, other snack and other eating event.

Daily aggregated food consumption and nutrient intake were calculated by in-house software that uses the Finnish food composition database ${ }^{(30)}$. The dietary data were converted to food consumption in seventy-six food groups ${ }^{(21)}$ from which eighteen food groups were chosen and aggregated for the analyses of the present study. For food consumption, and energy and nutrient intake, the mean intake over $2 \mathrm{~d}$ was calculated. Nutrient intake is expressed either as an energy percentage or intake per unit of energy (MJ).

\section{Statistical methods}

The associations between background variables and education were tested by $\chi^{2}$ test. The differences in nutrient intake between education categories were tested by ANOVA. Education was inserted into the model, first as a categorical variable and then as a continuous variable (trend test). For these analyses, the nutrient intake was converted into a logarithmic scale in order to improve normality.

The differences in food consumption between education categories were analysed with Kruskal-Wallis nonparametric test, since the food consumption variables 
were not normally distributed. These analyses were performed with consumption calculated in relation to energy intake (MJ). The associations between the determinants and facilitators of dietary behaviour and the intakes of SFA and PUFA were tested by ANOVA. The explanatory variables were included in the model in three ways: each background variable individually, all variables in the full model and finally, only the significant variables in the final model. All the models were adjusted in relation to age.

All the analyses were performed by using the SAS for Windows statistical software package version $8 \cdot 2$ (SAS Institute Inc., Cary, NC, USA). All analyses were performed separately for men and women, because there are differences by gender in socio-economic status and food behaviour.

\section{Results}

Daily dietary habits differed by educational category. Both women and men in the high-educational category had more frequent lunches at worksite cafeterias or in restaurants, and more often used oil in food preparation than others (Table 1). In women, use of ready-to-eat meals was most frequent in the high-educational category. By contrast, perception of a high $\mathrm{CV}$ risk, receiving dietary advice after previous cholesterol measurement, or following a cholesterol-lowering diet showed no difference by education. Basic health status was rated as poor by $11 \%$ in the low-educational category of women and by $4 \%$ in the high-education category and by $15 \%$ and $4 \%$ in men, respectively (Table 1 ). Similar trends were observed in functional capacity in women.

Educational category was associated with some differences in nutrient intakes in men and in women (Table 2). In the low-educational category, the diet of men contained less protein and carbohydrates, more fat and more SFA and MUFA than in higher-educational categories. In addition, the folate intake was smaller in the low-educational category than in the high category in men (Table 2). In women, the intakes of PUFA, vitamin $\mathrm{C}$, vitamin $\mathrm{E}$ and folate increased in the higher-educational category.

The diet of adults differed in vegetable and fruit consumption and the lowest consumption was observed in the low-educational category of both men and women. Adults with low education more frequently used mediumfat milk than those with higher education in both genders. The consumption of fat-free milk was higher with higher education only in men. The daily consumption of margarines that contained at least $60 \%$ fat and were used as spreads was higher in the low-educational categories of both genders (Table 3). Use of other spreads, butter or low-fat spreads, were not significantly associated with education. The consumption of oil dressing was lowest in women with low education. Furthermore, sausage consumption was more typical in the low-educational category and fish consumption in the high-educational category in women.

The association between the determinants and facilitators in dietary habits, education and the intakes of SFA and PUFA were studied by single and multiple regression analysis. In single ANOVA, education was a significant determinant for the intake of SFA in men, but not in women (Table 4). Both men and women following a cholesterol-lowering diet and reporting use of oil as cooking fat had lower intake of SFA compared to the others. Further, in women, frequent consumption of ready-to-eat meals was associated with higher intake of SFA. In men, having received previous dietary guidelines for lowering cholesterol was associated with the intake of SFA (Table 4), and a frequent habit of eating served

Table 1 Basic characteristics of dietary behaviour and health status in the adults of FINDIET 2007 by education

\begin{tabular}{|c|c|c|c|c|c|c|}
\hline & \multicolumn{6}{|c|}{ Educational category } \\
\hline & \multicolumn{3}{|c|}{ Women } & \multicolumn{3}{|c|}{ Men } \\
\hline & Low (n 272) & Middle (n 275) & High (n 294) & Low (n 240) & Middle (n 255) & High ( $n$ 230) \\
\hline & $\%$ & $\%$ & $\%$ & $\%$ & $\%$ & $\%$ \\
\hline \multicolumn{7}{|c|}{ Determinants and facilitators of dietary behaviour } \\
\hline High self-rated cardiovascular risk & 18 & 22 & 18 & 17 & 18 & 14 \\
\hline Following a cholesterol-lowering diet & 9 & 10 & 9 & 8 & 12 & 10 \\
\hline Previous dietary guidance & 37 & 42 & 42 & 53 & 50 & 54 \\
\hline Frequent lunches by caterers ${ }^{\star,} \dagger$ & 22 & 28 & 34 & 23 & 34 & 51 \\
\hline Oil used in cooking at home* $\dagger$ & 45 & 53 & 69 & 43 & 44 & 55 \\
\hline Ready-to-eat meals frequently* & 11 & 17 & 18 & 16 & 19 & 17 \\
\hline \multicolumn{7}{|l|}{ Health status } \\
\hline Poor self-rated health*† & 11 & 4 & 4 & 15 & 12 & 4 \\
\hline \multirow[t]{2}{*}{ Poor functional capacity ${ }^{\star}$} & 16 & 11 & 9 & 15 & 14 & 10 \\
\hline & Mean & $\mathrm{SD}$ & Mean & SD & Mean & SD \\
\hline Serum cholesterol & $5 \cdot 1$ & $5 \cdot 2$ & $5 \cdot 1$ & $5 \cdot 3$ & $5 \cdot 3$ & $5 \cdot 2$ \\
\hline Serum cholesterol & 0.9 & $1 \cdot 0$ & $0 \cdot 0$ & $1 \cdot 1$ & $1 \cdot 0$ & $1 \cdot \overline{0}$ \\
\hline
\end{tabular}

${ }^{*} P<0.05$ for differences in frequencies by education in $\chi^{2}$ test in women.

$+P<0.05$ for differences in frequencies by education in $\chi^{2}$ test in men. 
Table 2 Nutrient intake (E \% or per MJ energy intake) by education in FINDIET 2007

\begin{tabular}{|c|c|c|c|c|c|c|c|c|c|c|c|c|c|c|}
\hline \multirow[b]{4}{*}{ Nutrient } & \multicolumn{14}{|c|}{ Educational category } \\
\hline & \multicolumn{6}{|c|}{ Women } & \multicolumn{7}{|c|}{ Men } & \multirow[b]{3}{*}{$P$ for trenc } \\
\hline & \multicolumn{2}{|c|}{ Low ( $n$ 272) } & \multicolumn{2}{|c|}{ Middle ( $n$ 275) } & \multicolumn{2}{|c|}{ High (n 294) } & \multirow[b]{2}{*}{$P$ for trend } & \multicolumn{2}{|c|}{ Low (n 240) } & \multicolumn{2}{|c|}{ Middle ( $n$ 255) } & \multicolumn{2}{|c|}{ High (n 230) } & \\
\hline & Mean & SD & Mean & SD & Mean & SD & & Mean & SD & Mean & SD & Mean & SD & \\
\hline Energy (MJ) & $6 \cdot 6$ & $2 \cdot 1$ & $6 \cdot 6$ & $1 \cdot 8$ & $7 \cdot 1$ & $2 \cdot 1$ & 0.001 & $9 \cdot 4$ & $2 \cdot 9$ & $9 \cdot 4$ & $2 \cdot 9$ & $8 \cdot 9$ & $2 \cdot 7$ & \\
\hline Energy (kcal) & 1575 & 492 & 1587 & 439 & 1692 & 510 & & 2236 & 703 & 2245 & 697 & 2123 & 637 & \\
\hline Protein (E\%) & $17 \cdot 0$ & $4 \cdot 3$ & $17 \cdot 0$ & $3 \cdot 6$ & $17 \cdot 0$ & $4 \cdot 2$ & & $16 \cdot 0$ & $3 \cdot 4$ & 17 & 3.9 & 17 & $3 \cdot 6$ & 0.01 \\
\hline Fat (E\%) & $31 \cdot 0$ & $7 \cdot 7$ & $31 \cdot 0$ & $7 \cdot 2$ & $32 \cdot 0$ & $7 \cdot 3$ & & $35 \cdot 0$ & $7 \cdot 9$ & 32 & $7 \cdot 8$ & $32 \cdot 0$ & $7 \cdot 5$ & 0.001 \\
\hline SFA (E\%) & $12 \cdot 3$ & $4 \cdot 2$ & 11.9 & $3 \cdot 8$ & $11 \cdot 9$ & $3 \cdot 8$ & & $13 \cdot 9$ & $4 \cdot 4$ & $12 \cdot 5$ & $3 \cdot 9$ & $12 \cdot 2$ & $3 \cdot 9$ & 0.001 \\
\hline MUFA (E\%) & $10 \cdot 8$ & $3 \cdot 3$ & $10 \cdot 8$ & $3 \cdot 1$ & $11 \cdot 1$ & $3 \cdot 2$ & & $12 \cdot 7$ & $3 \cdot 6$ & $11 \cdot 8$ & $3 \cdot 5$ & $11 \cdot 6$ & $3 \cdot 3$ & 0.001 \\
\hline PUFA (E\%) & $5 \cdot 3$ & 1.9 & $5 \cdot 7$ & $2 \cdot 1$ & $6 \cdot 0$ & $2 \cdot 4$ & 0.002 & $6 \cdot 0$ & $2 \cdot 2$ & $5 \cdot 8$ & $2 \cdot 2$ & $5 \cdot 8$ & $2 \cdot 2$ & \\
\hline Carbohydrates (E\%) & $51 \cdot 0$ & $8 \cdot 0$ & 51 & $8 \cdot 0$ & $50 \cdot 0$ & $8 \cdot 0$ & & $46 \cdot 0$ & $9 \cdot 0$ & $48 \cdot 0$ & $9 \cdot 0$ & $48 \cdot 0$ & $9 \cdot 0$ & 0.02 \\
\hline Sucrose (E\%) & $10 \cdot 6$ & $5 \cdot 8$ & $10 \cdot 5$ & $4 \cdot 8$ & $10 \cdot 4$ & $4 \cdot 6$ & & $10 \cdot 0$ & $6 \cdot 6$ & $9 \cdot 7$ & $5 \cdot 8$ & $9 \cdot 4$ & $5 \cdot 3$ & \\
\hline Alcohol (E\%) & $1 \cdot 1$ & $4 \cdot 3$ & $1 \cdot 3$ & $3 \cdot 3$ & 1.5 & $3 \cdot 6$ & 0.01 & $2 \cdot 8$ & $6 \cdot 0$ & $3 \cdot 0$ & $6 \cdot 2$ & $3 \cdot 3$ & $6 \cdot 7$ & \\
\hline Fibre (g/MJ) & $3 \cdot 1$ & $1 \cdot 3$ & $3 \cdot 2$ & $1 \cdot 2$ & $3 \cdot 2$ & $1 \cdot 3$ & & $2 \cdot 5$ & $1 \cdot 1$ & $2 \cdot 8$ & $1 \cdot 2$ & $2 \cdot 7$ & $1 \cdot 1$ & \\
\hline Vitamin C (mg/MJ) & $17 \cdot 0$ & $12 \cdot 0$ & 19 & $13 \cdot 0$ & 20 & 13 & 0.001 & $9 \cdot 0$ & $9 \cdot 0$ & $12 \cdot 0$ & $10 \cdot 0$ & $12 \cdot 0$ & $10 \cdot 0$ & \\
\hline Vitamin E (mg/MJ) & $1 \cdot 1$ & $0 \cdot 4 \cdot 0$ & $1 \cdot 2$ & $0 \cdot 4$ & $1 \cdot 3$ & 0.5 & 0.001 & $1 \cdot 1$ & 0.4 & $1 \cdot 1$ & $0 \cdot 4 \cdot 0$ & $1 \cdot 1$ & $0 \cdot 4$ & \\
\hline Folate $(\mu \mathrm{g} / \mathrm{MJ})$ & $33 \cdot 5$ & $15 \cdot 0$ & 34.9 & $13 \cdot 0$ & $35 \cdot 1$ & $13 \cdot 0$ & 0.05 & $27 \cdot 9$ & $10 \cdot 0$ & $29 \cdot 8$ & $11 \cdot 0$ & $32 \cdot 0$ & $15 \cdot 0$ & 0.001 \\
\hline
\end{tabular}

$\mathrm{E} \%$, energy percentage.

Table 3 Food use for selected food groups $(\mathrm{g} / \mathrm{d})$ by educational category in women and men in FINDIET 2007

\begin{tabular}{|c|c|c|c|c|c|c|c|c|c|c|c|c|c|c|}
\hline \multirow[b]{4}{*}{ Food group } & \multicolumn{14}{|c|}{ Educational category } \\
\hline & \multicolumn{6}{|c|}{ Women } & \multicolumn{7}{|c|}{ Men } & \multirow[b]{3}{*}{$P$ for trend } \\
\hline & \multicolumn{2}{|c|}{ Low (n 272) } & \multicolumn{2}{|c|}{ Middle (n 275) } & \multicolumn{2}{|c|}{$\overline{\text { High (n 294) }}$} & \multirow{2}{*}{$P$ for trend* } & \multicolumn{2}{|c|}{ Low (n 240) } & \multicolumn{2}{|c|}{ Middle (n 255) } & \multicolumn{2}{|c|}{$\overline{\text { High (n 230) }}$} & \\
\hline & Mean & SD & Mean & SD & Mean & SD & & Mean & SD & Mean & SD & Mean & SD & \\
\hline Vegetable (fresh, cooked) & 134 & 125 & 161 & 136 & 187 & 150 & $<0.001$ & 100 & 107 & 117 & 119 & 132 & 126 & $<0.001$ \\
\hline Fruit (including dishes) & 129 & 132 & 149 & 157 & 175 & 158 & 0.007 & 85 & 159 & 128 & 184 & 123 & 190 & $<0.001$ \\
\hline Berries & 48 & 82 & 55 & 85 & 52 & 90 & & 30 & 69 & 48 & 93 & 42 & 85 & 0.018 \\
\hline Dark bread & 100 & 59 & 97 & 61 & 98 & 62 & & 147 & 98 & 156 & 110 & 128 & 75 & \\
\hline Bakery & 75 & 78 & 78 & 84 & 72 & 77 & & 101 & 117 & 96 & 115 & 113 & 112 & 0.013 \\
\hline Porridge & 77 & 107 & 76 & 110 & 71 & 111 & & 58 & 111 & 91 & 149 & 81 & 127 & 0.038 \\
\hline Potatoes & 63 & 65 & 56 & 63 & 54 & 63 & 0.049 & 98 & 97 & 93 & 87 & 81 & 80 & \\
\hline Butter spreads & 5 & 12 & 4 & 9 & 4 & 8 & & 10 & 23 & 7 & 17 & 6 & 13 & \\
\hline Margarines ( $\geq 60 \%$ fat) & 6 & 12 & 4 & 9 & 3 & 7 & 0.042 & 13 & 22 & 10 & 22 & 5 & 10 & 0.024 \\
\hline Low-fat spreads & 7 & 12 & 7 & 11 & 7 & 15 & & 9 & 20 & 11 & 22 & 9 & 15 & \\
\hline Oil dressing & 2 & 6 & 4 & 8 & 4 & 9 & $<0.001$ & 4 & 13 & 3 & 9 & 6 & 12 & $<0.001$ \\
\hline Milk fat-free & 113 & 189 & 126 & 199 & 108 & 180 & & 100 & 228 & 158 & 299 & 150 & 264 & 0.002 \\
\hline Milk medium fat & 113 & 189 & 66 & 136 & 58 & 117 & $<0.001$ & 206 & 291 & 171 & 297 & 110 & 209 & $<0.001$ \\
\hline Cheese & 26 & 29 & 28 & 31 & 34 & 38 & 0.043 & 34 & 46 & 34 & 41 & 34 & 34 & \\
\hline Meat dishes & 134 & 118 & 130 & 111 & 127 & 115 & & 184 & 147 & 197 & 158 & 176 & 140 & \\
\hline Sausages & 33 & 41 & 25 & 31 & 19 & 30 & $<0.001$ & 67 & 74 & 56 & 63 & 46 & 56 & 0.040 \\
\hline Fish dishes & 28 & 63 & 40 & 65 & 42 & 67 & $<0.001$ & 41 & 86 & 49 & 103 & 40 & 71 & \\
\hline Sweet and chocolate & 17 & 29 & 16 & 26 & 19 & 31 & & 12 & 30 & 11 & 26 & 14 & 28 & \\
\hline
\end{tabular}

${ }^{*}$ Differences between educational categories were tested with non-parametric Kruskall-Wallis test for food consumption per $1 \mathrm{MJ}$ energy intake.

lunches was associated with higher intake of PUFA (Table 5). Oil used in cooking at home was significantly associated with the increasing intake of PUFA in women.

In the final multiple regression model, only significant background factors and age were included (Tables 4 and 5). The high-educational category was associated with a lower intake of SFA in men and a higher intake of PUFA in women. Following a cholesterol-lowering diet was associated with a lower intake of SFA in both genders in the final model, and in women, who used oil in cooking at home. The final model accounted for $5.7 \%$ of the variance in the intake of SFA in women and $5.0 \%$ of the variance in men. The final multiple model for the determinants of the intakes of PUFA was significant only for women.

\section{Discussion}

Some dietary behaviours and determinants were influencing the intakes of SFA and PUFA in Finnish adults. Preventive cardiology aims to change the quality of dietary fat in at-risk-populations as well as across the entire population ${ }^{(6,8,10)}$. We wanted to explore the determinants and facilitators of dietary fat quality in this cross-sectional population survey. A favourable trend by increasing education was observed for the decreasing 
Table 4 The associations of educational category and facilitators of dietary behaviour with the intakes of SFA

\begin{tabular}{|c|c|c|c|c|c|c|}
\hline & \multicolumn{2}{|c|}{ Single variables in model ${ }^{*}$} & \multicolumn{2}{|c|}{ Full model $^{*}$} & \multicolumn{2}{|c|}{ Final model* } \\
\hline & Women & Men & Women & Men & Woment & Men‡ \\
\hline \multicolumn{7}{|l|}{ Education } \\
\hline Low & 0.3333 & $1 \cdot 7148$ & -0.0209 & $1 \cdot 4143$ & & $1 \cdot 6573$ \\
\hline Middle & -0.0760 & 0.2514 & -0.2476 & -0.0504 & & $0 \cdot 2201$ \\
\hline High (reference) & - & - & - & - & & - \\
\hline$P$ value & NS & $<0.001$ & NS & $<0.001$ & & $<0.001$ \\
\hline \multicolumn{7}{|l|}{ Cholesterol-lowering diet } \\
\hline No diet & $1 \cdot 6619$ & $1 \cdot 6824$ & $1 \cdot 4403$ & $1 \cdot 4323$ & $1 \cdot 5187$ & 1.6570 \\
\hline Following diet (reference) & - & - & - & - & - & - \\
\hline$P$ value & $<0.001$ & 0.001 & 0.005 & 0.009 & 0.001 & 0.001 \\
\hline \multicolumn{7}{|l|}{ Previous dietary guidance } \\
\hline Not received & 0.5370 & $0 \cdot 7692$ & 0.2746 & 0.5371 & & \\
\hline Received (reference) & - & - & - & - & & \\
\hline$P$ value & 0.082 & 0.018 & NS & NS & & \\
\hline \multicolumn{7}{|l|}{ Lunches served by caterers } \\
\hline Frequently & 0.0388 & 0.6009 & $0 \cdot 1412$ & $0 \cdot 2667$ & & \\
\hline Rarely (reference) & - & - & - & - & & \\
\hline$P$ value & NS & 0.065 & NS & NS & & \\
\hline \multicolumn{7}{|l|}{ Cooking fat at home } \\
\hline Hard fat & $1 \cdot 5421$ & $0 \cdot 8278$ & $1 \cdot 4903$ & 0.5144 & $1 \cdot 4938$ & \\
\hline Oil (reference) & - & - & - & - & - & \\
\hline$P$ value & $<0.001$ & 0.007 & $<0.001$ & NS & $<0.001$ & \\
\hline \multicolumn{7}{|l|}{ Ready-to-eat meals } \\
\hline Frequently & $0 \cdot 7983$ & -0.0640 & $0 \cdot 7818$ & $-0 \cdot 2266$ & & \\
\hline Rarely (reference) & - & - & - & - & & \\
\hline$P$ value & 0.035 & NS & 0.043 & NS & & \\
\hline \multicolumn{7}{|l|}{ Cardiovascular risk } \\
\hline Perceived high & -0.0049 & $0 \cdot 2905$ & $0 \cdot 2821$ & 0.4515 & & \\
\hline Perceived low (reference) & - & - & - & - & & \\
\hline$P$ value & NS & NS & NS & NS & & \\
\hline
\end{tabular}

*Adjusted for age.

$+R^{2}=0.058, F=3.816 ; P<0.001$.

$\ddagger R^{2}=0.050, F=6,699 ; P<0.001$.

intake of SFA in men and for the increasing intake of PUFA in women, corresponding to earlier results ${ }^{(12,13,16)}$. Our results showed that certain dietary behaviours were associated with dietary fat quality in the multiple model in which all significant background variables were included. Following a cholesterol-lowering diet was associated with a decreasing intake of SFA both in women and men, which is an encouraging results for practices with limited time in primary health care ${ }^{(24)}$. However, in order to change the fat quality of the diet, an increased average intake of PUFA is needed. It seems obvious that the consumption of oil and margarines has not been fully adopted.

The possible determinants and facilitators of dietary behaviour such as selection of cooking fat, frequency of eating served lunches or ready-to-eat meals varied by education, whereas following a cholesterol-lowering diet did not. The background data of the present study included only limited facilitators by which subjects could have aimed to decrease their serum cholesterol category by personal dietary changes compared with previous studies $^{(10,26)}$. However, a more systematic list of facilitators has revealed only weak associations with dietary fat quality ${ }^{(10)}$ although change-motivation has affected the total fat intake ${ }^{(20)}$. By contrast, worksite cafeterias ${ }^{(18)}$ and school canteens ${ }^{(26)}$ have been reported to be good facilitators for healthy eating.
The serum cholesterol level did not differ by education in the subjects of FINDIET 2007. However, the mean cholesterol was above the recommended level in all groups and thus the recommendation for decreasing the intake of saturated fat is applicable for the majority of the population ${ }^{(9)}$. A limitation of the present study is the higher non-participation of subjects with lower education and younger age groups, which may have affected the results of cholesterol levels.

According to the present results, women in all educational categories have the same intake of total fat and SFA, but intake of PUFA was higher with higher education. By contrast, the intake of SFA was significantly higher in men with low education compared to men with higher education. One way of changing the fat content of diets towards more unsaturated fats is the use of oil in food preparation and salad dressings, which seems to be applied by highly educated people, but which still needs to be adopted by less-educated women. However, the selection of low-fat spreads is even in educational groups, and it may not be a tool to increase the intake of PUFA.

Most differences in food use and nutrient intake by education corresponded to previous studies ${ }^{(12,13,16,17,31)}$. The higher consumption of cheese in the high-educational category compensates for the higher consumption of medium-fat milk in the low-educational category, and 
Table 5 The association of educational category and facilitators of dietary change with the intakes of PUFA

\begin{tabular}{|c|c|c|c|c|c|c|}
\hline & \multicolumn{2}{|c|}{ Single variables in model $^{*}$} & \multicolumn{2}{|c|}{ Full model* } & \multicolumn{2}{|c|}{ Final model ${ }^{*}$} \\
\hline & Women & Men & Women & Men & Woment & Men \\
\hline \multicolumn{7}{|l|}{ Education } \\
\hline Low & -0.6512 & $0 \cdot 1734$ & -0.5909 & $0 \cdot 3143$ & -0.5832 & \\
\hline Middle & $-0 \cdot 3014$ & -0.0305 & -0.2896 & 0.0687 & -0.2336 & \\
\hline High (reference) & - & - & - & - & - & \\
\hline$P$ value & $<0.001$ & NS & 0.002 & NS & 0.002 & \\
\hline \multicolumn{7}{|l|}{ Cholesterol-lowering diet } \\
\hline No diet & $-0 \cdot 3221$ & $-0 \cdot 4815$ & $-0 \cdot 2846$ & -0.5122 & & \\
\hline Following diet (reference) & - & - & - & - & & \\
\hline$P$ value & NS & 0.086 & NS & 0.093 & & \\
\hline \multicolumn{7}{|l|}{ Previous dietary guidance } \\
\hline Not received & $-0 \cdot 1333$ & -0.001 & -0.0250 & $0 \cdot 1545$ & & \\
\hline Received (reference) & - & - & - & - & & \\
\hline$P$ value & NS & NS & NS & NS & & \\
\hline \multicolumn{7}{|l|}{ Lunches served by caterers } \\
\hline Frequently & 0.0124 & 0.3939 & $0 \cdot 1629$ & 0.4067 & & 0.3939 \\
\hline Rarely (reference) & - & - & - & - & & - \\
\hline$P$ value & NS & 0.025 & NS & 0.030 & & 0.025 \\
\hline \multicolumn{7}{|l|}{ Cooking fat at home } \\
\hline Hard fat & $-0 \cdot 3994$ & $-0 \cdot 3038$ & $-0 \cdot 2846$ & $-0 \cdot 2600$ & $-0 \cdot 2999$ & \\
\hline Oil (reference) & - & - & - & - & - & \\
\hline$P$ value & 0.008 & 0.063 & 0.075 & NS & 0.0049 & \\
\hline \multicolumn{7}{|l|}{ Ready-to-eat meals } \\
\hline Frequently & -0.0908 & $0 \cdot 0027$ & $-0 \cdot 1047$ & 0.0535 & & \\
\hline Rarely (reference) & - & - & - & - & & \\
\hline$P$ value & NS & NS & NS & NS & & \\
\hline \multicolumn{7}{|l|}{ Cardiovascular risk } \\
\hline Perceived high & 0.0387 & $0 \cdot 1310$ & 0.0422 & $0 \cdot 1502$ & & \\
\hline Perceived low (reference) & - & - & - & - & & \\
\hline$P$ value & NS & NS & NS & NS & & \\
\hline
\end{tabular}

${ }^{*}$ Adjusted for age.

$+R^{2}=0.021, F=6.831 ; P=0.007$.

$\ddagger R^{2}=0.011, F=4 \cdot 704 ; P=0.089$.

results in a similar intake of SFA in women. In addition, the use of ready-to-eat meals was more frequent in highly educated women. This could be interpreted to suggest that a frequent consumption of ready-to-eat meals is associated with a diet of less-controlled fat quality ${ }^{(19)}$. Some differences in nutrient intakes by education were clear, e.g. for vitamin $\mathrm{C}$ intake in women, but the mean intake was, however, above the recommended level in all educational groups.

Food preparation skills have been reported as being associated with healthy eating in earlier studies ${ }^{(16,22,23)}$. Our results supported these findings with the association between dietary fat quality and cooking fat used at home, but this association was found in women only. It has been postulated that the population may benefit more from messages that emphasize fat quality rather than from messages that focus on fat quantity ${ }^{(32)}$. The quantity of fat and type of fat are the main themes in counselling sessions that have a mean duration of $5 \mathrm{~min}$ in counselling sessions with nurses, or $3 \mathrm{~min}$ in counselling sessions with physicians ${ }^{(24)}$. It is possible that women can achieve a better implementation of recommendations from a few words with the counsellor than men. On the contrary, the frequent consumption of lunches served through catering was associated with the intake of PUFA in men. This may be due to oil and oil dressing used in vegetable salads in restaurant or worksite cafeterias more than the type of cooking fat used by catering service. This may also be associated with the fact that in an interview concerning previous days, the subject is not able to give information on the cooking fat used by the caterer. The meals served by catering departments seem to have a desirable effect on the dietary fat quality in men ${ }^{(12)}$. In the present study, we could not study any actual changes in the dietary contributors of SFA, because the changes after dietary advice were not assessed.

Dietary counselling in primary health care also includes type of spread on bread ${ }^{(24)}$. However, the effect of spreads on the total intake of SFA has been decreasing due to the high proportion of low-fat spreads. In line with this, the only significant difference in the consumption of fat spreads was the higher consumption of margarines containing at least $60 \%$ fat in the low-educational category. The identification of cooking fat was used in the present study as an index of dietary fat selection that supported the results of a previous study ${ }^{(16)}$.

In conclusion, the fat quality of diets is still dependent on educational category. Food choices such as type of milk and fat used in cooking partly explain the differences in the fat quality of diets. In addition to education, 
following a cholesterol-lowering diet was associated with decreased intake of SFA in men, and oil used in cooking at home with increased intake of PUFA in women. These associations may be due to general health messages or achievements by health professionals. The results indicate that personal intentions in the control of dietary fat quality are worth further study. Finally, the national nutritional recommendations ${ }^{(9)}$ favouring visible vegetable-based fat and oil, and avoiding hard fat hiding in mixed foods, are relevant.

\section{References}

1. Laaksonen M, Talala K, Martelin T et al. (2008) Health behaviours as explanations for educational level differences in cardiovascular and all-cause mortality: a follow-up of 60000 men and women over 23 years. Eur J Public Health 18, 38-43.

2. Palosuo H, Koskinen S, Lahelma E et al. (editors) (2009) Health Inequalities in Finland. Trends in Socioeconomic Health Differences 1980-2005. Publications of the Ministry of Social Affairs and Health 2009:9. Helsinki: University Press; available at http://www.stm.fi/c/document_library/ get_file?folderId=39503\&name=DLFE-8648.pdf

3. Sarlio-Lähteenkorva S, Silventoinen $\mathrm{K}$, Lahti-Koski M et al. (2006) Socio-economic status and abdominal obesity among Finnish adults from 1992 to 2002. Int J Obes (Lond) 30, 1653-1660.

4. Vartiainen E, Puska P, Pekkanen J et al. (1994) Changes in risk factors explain changes in mortality from ischaemic heart disease in Finland. BMJ 309, 23-27.

5. Valsta L, Tapanainen H, Laatikainen $\mathrm{T}$ et al. (2009) Explaining the 25-year decline of serum cholesterol by dietary changes and use of lipid lowering medication in Finland. Public Health Nutr (in this issue).

6. Salomaa V, Laatikainen T, Tapanainen H et al. (2003) Sepelvaltimotaudin riskitekijöiden sosioekonomiset erot (In Finnish, summary in English: The role of socioeconomic differences in the prevalence and prevention of CHD). Suom Lääkäril 58, 3187-3191.

7. Vartiainen E, Peltonen M, Laatikainen $\mathrm{T}$ et al. (2008) Cardiovascular risk factor changes in the FINRISK Study from 1982 to 2007. Suom Lääkäril 63, 1375-1381.

8. Duodecim (2004) Dyslipidemia Best practice recommendation. Duodecim 120, 1794-1816.

9. National Nutrition Council (2005) Suomalaiset Ravitsemussuositukset (In Finnish, title in English: Finnish Nutrition Recommendations - Diet and Physical Activity in Balance). Committee report. Helsinki: Edita Publishing Oy; at available http://www.evira.fi/portal/vrn/en/nutrition_ recommendations/

10. Koikkalainen M, Mykkänen H, Erkkilä A et al. (1999) Difficulties in changing the diet in relation to dietary fat intake among patients with coronary heart disease. Eur J Clin Nutr 53, 120-125.

11. Helakorpi S, Prättälä R \& Uutela A (2008) Suomalaisen Aikuisväestön Terveyskäyttäytyminen ja Terveys, Kevät 2007 (In Finnish, tables, figures and summary in English: Health Behaviour and Health among the Finnish Adult Population, Spring 2007). Publications of the National Public Health Institute B6/2008. Helsinki: Yliopistopaino; available at http://www.ktl.fi/attachments/suomi/julkaisut/ julkaisusarja_b/2008/2008b06.pdf

12. Roos E, Lahelma E, Virtanen M et al. (1998) Gender, socioeconomic status and family status as determinants of food behaviour. Soc Sci Med 46, 1519-1529.
13. Hupkens CL, Knibbe RA \& Drop MJ (1997) Social class differences in women's fat and fibre consumption: a crossnational study. Appetite 28, 131-149.

14. Giskes K, Turrell G, van Lenthe FJ et al. (2006) A multilevel study of socio-economic inequalities in food choice behaviour and dietary intake among the Dutch population: the GLOBE study. Public Health Nutr 9, 75-83.

15. Hulshof KF, Brussaard JH, Kruizinga AG et al. (2003) Socioeconomic status, dietary intake and 10 y trends: the Dutch National Food Consumption Survey. Eur J Clin Nutr 57, 128-137.

16. Erkkilä AT, Sarkkinen ES, Lehto S et al. (1999) Diet in relation to socioeconomic status in patients with coronary heart disease. Eur J Clin Nutr 53, 662-668.

17. Dynesen AW, Haraldsdottir J, Holm L et al. (2003) Sociodemographic differences in dietary habits described by food frequency questions - results from Denmark. Eur J Clin Nutr 57, 1586-1597.

18. Roos E, Sarlio-Lahteenkorva S \& Lallukka T (2004) Having lunch at a staff canteen is associated with recommended food habits. Public Health Nutr 7, 53-61.

19. Beydoun MA, Powell LM \& Wang Y (2008) The association of fast food, fruit and vegetable prices with dietary intakes among US adults: is there modification by family income? Soc Sci Med 66, 2218-2229.

20. Glanz K, Patterson RE, Kristal AR et al. (1994) Stages of change in adopting healthy diets: fat, fiber, and correlates of nutrient intake. Health Educ Q 21, 499-519.

21. Paturi M, Tapanainen H, Reinivuo H et al. (editors) (2008) The National FINDIET 2007 Survey (In Finnish, tables, figures and summary in English). Publications of the National Public Health Institute B23/2008. Helsinki: Yliopistopaino; available at http://www.ktl.fi/attachments/ suomi/julkaisut/julkaisusarja_b/2008/2008b23.pdf

22. Larson NI, Perry CL, Story M et al. (2006) Food preparation by young adults is associated with better diet quality. $J \mathrm{Am}$ Diet Assoc 106, 2001-2007.

23. Lappalainen R, Saba A, Holm L et al. (1997) Difficulties in trying to eat healthier: descriptive analysis of perceived barriers for healthy eating. Eur J Clin Nutr 51, Suppl. 2, S36-S40.

24. Poskiparta M, Kasila K \& Kiuru P (2007) Dietary and physical activity counselling on type 2 diabetes and impaired glucose tolerance by physicians and nurses in primary healthcare in Finland. Scand J Prim Health Care 24, 206-210.

25. Barker M, Lawrence W, Woadden J et al. (2008) Women of lower educational attainment have lower food involvement and eat less fruit and vegetables. Appetite 50, 464-468.

26. Shepherd J, Harden A, Rees R et al. (2006) Young people and healthy eating: a systematic review of research on barriers and facilitators. Health Educ Res 21, 239-257.

27. Vartiainen E, Peltonen M, Laatikainen $\mathrm{T}$ et al. (2008) FINRISKI-tutkimus: Sekä miesten että naisten sydän - ja verisuonisairauksien kokonaisriski pieneni viime vuosina (In Finnish, summary in English: Cardiovascular risk factor changes in the FINRISK Study from 1982 to 2007). Suom Lääkaril 63, 1375-1381.

28. Reinivuo H, Hirvonen T, Ovaskainen M-L et al. (2010) Dietary survey methodology of FINDIET 2007 with a risk assessment perspective. Public Health Nutr (in this issue).

29. Pietinen P, Paturi M, Reinivuo H et al. (2010) FINDIET 2007 Survey: energy and nutrient intakes. Public Health Nutr (in this issue).

30. National Institute for Health and Welfare (2009) Fineli Finnish Food Composition Database. 2008 ed. http://www. fineli.fi/index.php?lang =en

31. Lallukka T, Laaksonen M, Rahkonen O et al. (2007) Multiple socio-economic circumstances and healthy food habits. Eur J Clin Nutr 61, 701-710.

32. Erkkilä A, de Mello VD, Riserus U et al. (2008) Dietary fatty acids and cardiovascular disease: an epidemiological approach. Prog Lipid Res 47, 172-187. 